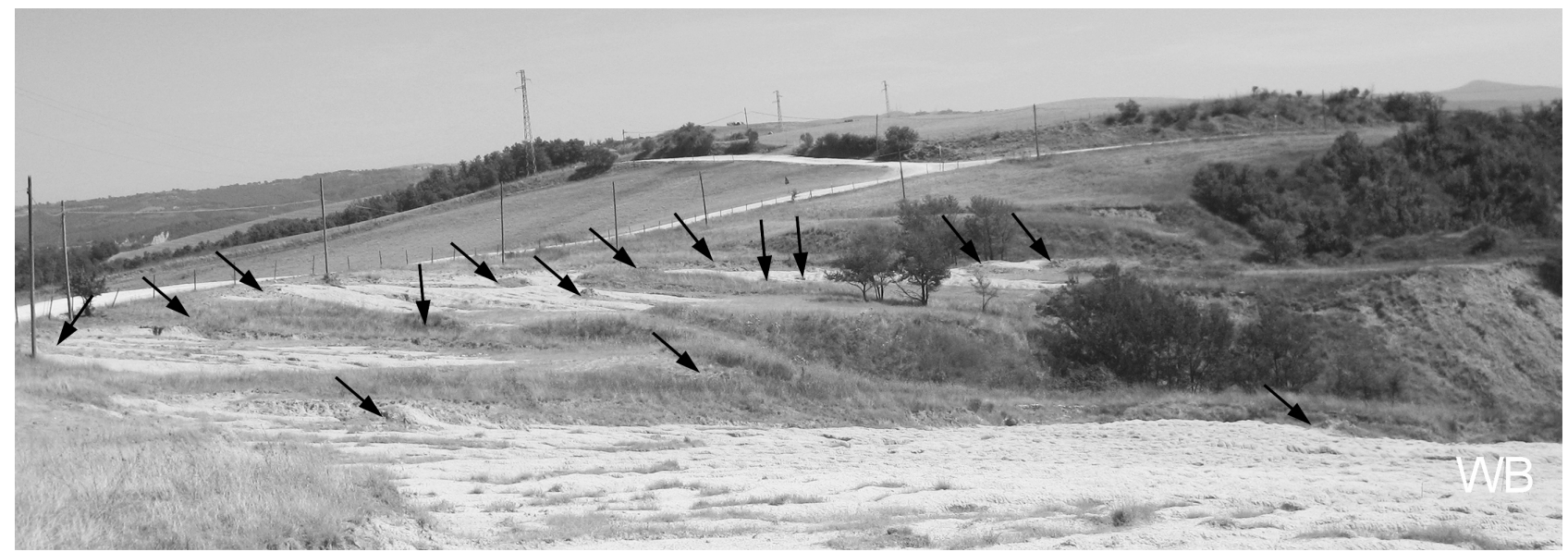

Figure DR 1. Overview of fossil structures (arrows) in the clay deposits of Allerona (Umbria, central Italy). 


\begin{tabular}{|c|c|c|c|}
\hline MOLLUSK Assemblage & This paper & $\begin{array}{l}\text { Dominici et } \\
\text { al. } 2010\end{array}$ & $\begin{array}{l}\text { Danise et } \\
\text { al. } 2010\end{array}$ \\
\hline \multicolumn{4}{|l|}{ SCAPHOPODA } \\
\hline Dentalium fossile & $\mathrm{x}$ & & \\
\hline Dentalium sexangulum & $\mathrm{x}$ & & \\
\hline \multicolumn{4}{|l|}{ GASTROPODA } \\
\hline Euspira catena & $\mathrm{x}$ & & \\
\hline Epitonium $\mathrm{sp}$ & $\mathbf{x}$ & $\mathbf{x}$ & $\mathbf{x}$ \\
\hline Haustator vermicularis & $\mathrm{x}$ & & \\
\hline Nassarius italicus (PO) & $\mathbf{x}$ & & $\mathbf{x}$ \\
\hline Ringicula auriculata $(\mathrm{PO})$ & $\mathbf{x}$ & $\mathbf{x}$ & $\mathbf{x}$ \\
\hline Turritella spirata & $\mathbf{x}$ & $\mathbf{x}$ & $\mathbf{x}$ \\
\hline $\begin{array}{l}\text { Turritella tricarinata } \\
\text { pliorecens }\end{array}$ & $\mathbf{x}$ & $\mathbf{x}$ & \\
\hline \multicolumn{4}{|l|}{ BIVALVIA } \\
\hline Aequipecten opercolaris & $\mathrm{x}$ & & \\
\hline Amusium cristatum (SF) & $\mathbf{x}$ & $\mathbf{x}$ & $\mathbf{x}$ \\
\hline Anadara diluvii (SF) & $\mathbf{x}$ & $\mathbf{x}$ & $\mathbf{x}$ \\
\hline Corbula gibba & $\mathbf{x}$ & $\mathbf{x}$ & $\mathbf{x}$ \\
\hline Glans intermedia & $\mathrm{x}$ & & \\
\hline Glossus humanus & $\mathbf{x}$ & $\mathbf{x}$ & \\
\hline $\begin{array}{l}\text { Megaxinus incrassatus } \\
(\mathrm{CH})\end{array}$ & $\mathbf{x}$ & $\mathbf{x}$ & $\mathbf{x}$ \\
\hline Myrtea spinifera $(\mathrm{CH})$ & $\mathbf{x}$ & $\mathbf{x}$ & \\
\hline Neopycnodonte cochlear & $\mathrm{x}$ & & \\
\hline Nucula placentina & $\mathbf{x}$ & & $\mathbf{x}$ \\
\hline Nuculana fragilis & $\mathbf{x}$ & $\mathbf{x}$ & $\mathbf{x}$ \\
\hline Ostrea lamellosa & $\mathrm{x}$ & & \\
\hline Pecten jacobaeus & $\mathrm{x}$ & & \\
\hline Venus multilamella & $\mathrm{x}$ & & \\
\hline
\end{tabular}

Table DR1. Comparison with mollusk whale fall community, reported by Danise et al. (2010) and Dominici et al. (2010) and assemblages found close to the whale bones and in the vicinity of the biogenic masses. $\mathrm{CH}$ - Chemosynthetic bivalves, sulphophilic stage; PO - species that food the polychaetes organic compounds; SF - suspension feeding. 
Appendix. Chemic analytical methods

- FT-IR analyses were carried out with a Bruker spectrometer, model TENSOR 27; the spectral collection was achieved using a $\mathrm{KBr}$ pellet of dry powder with a $2 \mathrm{~cm}^{-1}$ resolution; $2 \mathrm{mg}$ dry powder of bulk grey (grey line) and external red/yellow (black line) areas of the samples were dissolved in $100 \mathrm{mg} \mathrm{KBr}$ and pressed to obtain transparent disks. Figure DR2 shows representative spectra of grey and red/yellow areas: two definite spectral patterns are recognized on both types of samples. Absorption peaks at 725, 876, 1437, 2529 and $2920 \mathrm{~cm}^{-1}$ are ascribed (Andersen and Brečević, 1991) to $\mathrm{CaCO}_{3}$; features at 466, 515.5, 776, 796, 1028, 1079, 1162 and $1812 \mathrm{~cm}^{-1}$ to aluminium silicates (Madejová, 2003). (See Andersen and Brečević, 1991, and Madejová, 2003 for acronyms) - Liquid-chromatography analysis was carried out on a methanolic extract of five samples; qualitative determination of the organic compounds was done with an Agilent 6540 UHD accurate mass LCMS Q-TOF. The untargeted compounds (score $>95 \%$ ) were identified with the support of a METLINE accurate mass database (27,000 natural compounds and metabolites).

The preliminary chemical analyses evidenced many organic compounds of lipids derivation with a different distribution with respect to the type of sample. In particular in structure samples S2 and S3 were found anandamide, dodecadienoic, stearic, myristic and tridecadienoic acids, N-AcylEthanolamine, PGE2-alpha diethanolamine and the tripeptide Trp-Arg-Leu. Into the samples S4 and S5 were found sphingosine, dihydrosphingosine, oleic and palmitoleic acids, linoleamide, oleamide, octadecenamide and hexadecanal. Into the S1 samples was found a low level of oleamide, hexadecanal, sphingosine, dehydrosphingosine and phytosphingosine; the presence of anandamide, one endogen substance produced only by mammalians, supports the animal origin of structure analysed.

The eight free amino acid traces found in sample S2 and S3 (from biostructure) and S1 (clay below the structure) are compared (Table DR2) with squid beak composition of Dosidicus gigas, reported by Miserez et al. (2007)

\section{REFERENCES CITED}

Andersen, F.A., and Brečević, L., 1991, Infrared spectra of amorphous and crystalline calcium carbonate: Acta Chemica Scandinavica, v. 45, p. 1018-1024.

Madejová, J., 2003, FTIR techniques in clay mineral studies: Vibrational Spectroscopy, v. 31, p. 110.

Miserez, A., Li, Y., Waite, J.H., and Zok, F., 2007, Jumbo squid beaks: inspiration for design of robust organic composites: Acta Biomateralia, v. 3, p. 139-149. 


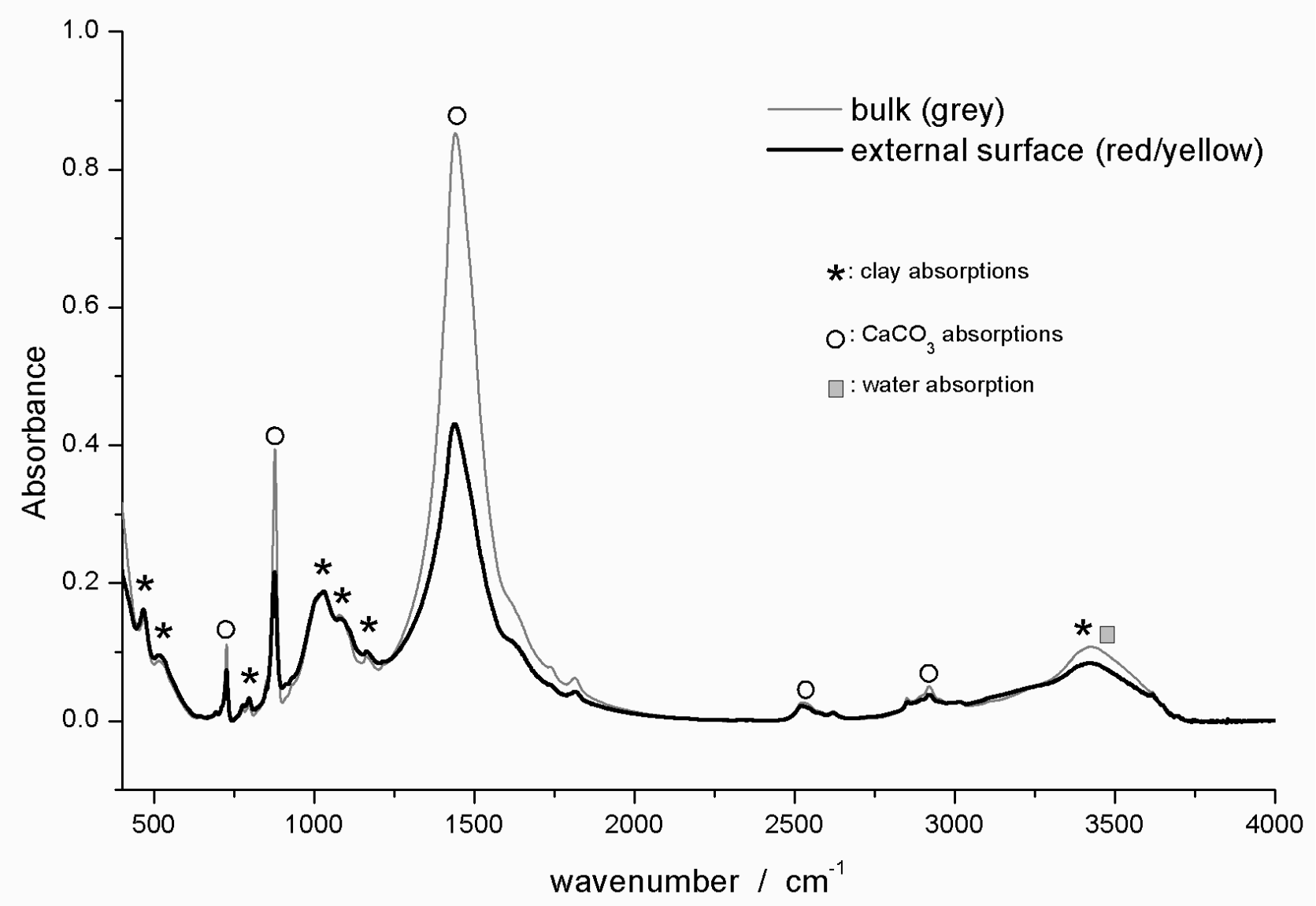

Figure DR2. Transmission FTIR spectra of fossil structures. $2 \mathrm{mg}$ dry powder of bulk grey (grey line) and external red/yellow (black line) areas of the samples were dissolved in $100 \mathrm{mg} \mathrm{KBr}$ and pressed to obtain transparent disks. The measured spectral profiles have been normalized to the intensities of silicate absorptions (see text). Spectral feature at $3400 \mathrm{~cm}^{-1}$ ca. is due to the overlapping of water and clay vibrations ( $\mathrm{OH}$ stretching modes). 


\begin{tabular}{|c|c|c|c|c|c|c|}
\hline \multirow{2}{*}{$\begin{array}{c}\text { Amino acid } \\
\text { (Miserez et al., 2007) }\end{array}$} & \multirow[t]{2}{*}{$\%$} & \multicolumn{5}{|c|}{ Samples of structures and clay sediments } \\
\hline & & $\mathrm{S} 1^{*}$ & $\mathrm{~S} 2 *$ & $\mathrm{~S} 3 *$ & $\mathrm{~S} 4 *$ & $\mathrm{~S} 5 *$ \\
\hline Aspartic acid (asp) & 6 & & & & & . \\
\hline Threonine (thr) & 2 & . & . & . & . & . \\
\hline Serine (ser) & 3 & 4,5 & 0,95 & 0,6 & 0 & 0,35 \\
\hline Glutamic acid (glu) & 5 & 0 & 0,35 & 1,15 & 0,75 & 0,25 \\
\hline Proline (pro) & 1 & 0 & 1,15 & 1,2 & 1,05 & 1 \\
\hline Glycine (gly) & 27 & 3,85 & 0,85 & 0,55 & 0,4 & 0,35 \\
\hline Alanine (ala) & 15 & 0,125 & 0,14 & 0,35 & 0,05 & 0,25 \\
\hline Valine (val) & 3 & 0,45 & 0,1 & 0,2 & 0,2 & 0,05 \\
\hline Isoleucine (ile) & 5 & 0,45 & 0,1 & 0,3 & 0,1 & 0,5 \\
\hline Leucine (leu) & 9 & 0,45 & 0,1 & 0,3 & 0,1 & 0,5 \\
\hline DOPA & $<1$ & \multirow{6}{*}{\multicolumn{5}{|c|}{$\begin{array}{l}\text { * values micrograms/g } \\
\text { S1: clay sediments drawn under structure; S2 and } \\
\text { S3: samples of structure; S4 and S5: samples coming far } \\
\text { from the structures }\end{array}$}} \\
\hline Tyrosine (tyr) & 3 & & & & & \\
\hline Phenylalanine (phe) & 5 & & & & & \\
\hline Histidine (his) & 11 & & & & & \\
\hline Lysine (1ys) & 1 & & & & & \\
\hline Arginine (arg) & 1 & & & & & \\
\hline
\end{tabular}

Table DR2. Distribution of free amino acids (FAA) traces found among samples and comparison with data supplied by Miserez et al., (2007), concerning the Dosidicus gigas jumbo squid beak composition. 


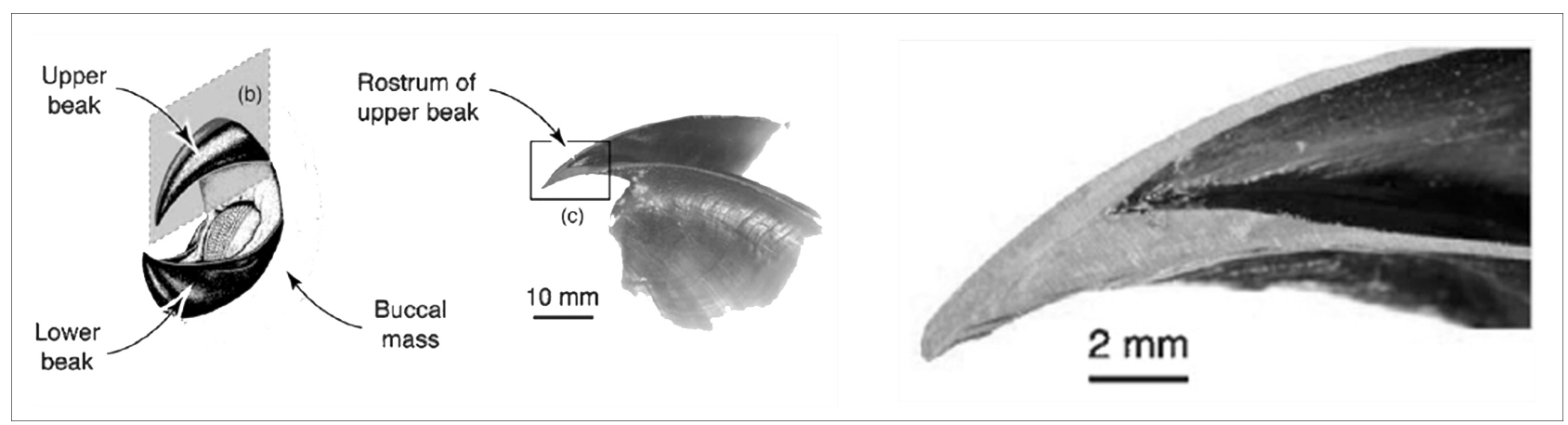

Figure DR3. Schematic view of modern squid beaks (modified after Xavier \& Cherel, 2009).

\section{REFERENCE CITED}

Xavier, J. C., and Cherel, Y., 2009, Cephalopod Beak Guide for the Southern Ocean: British Antarctic Survey, Cambridge, UK, 129 p. 


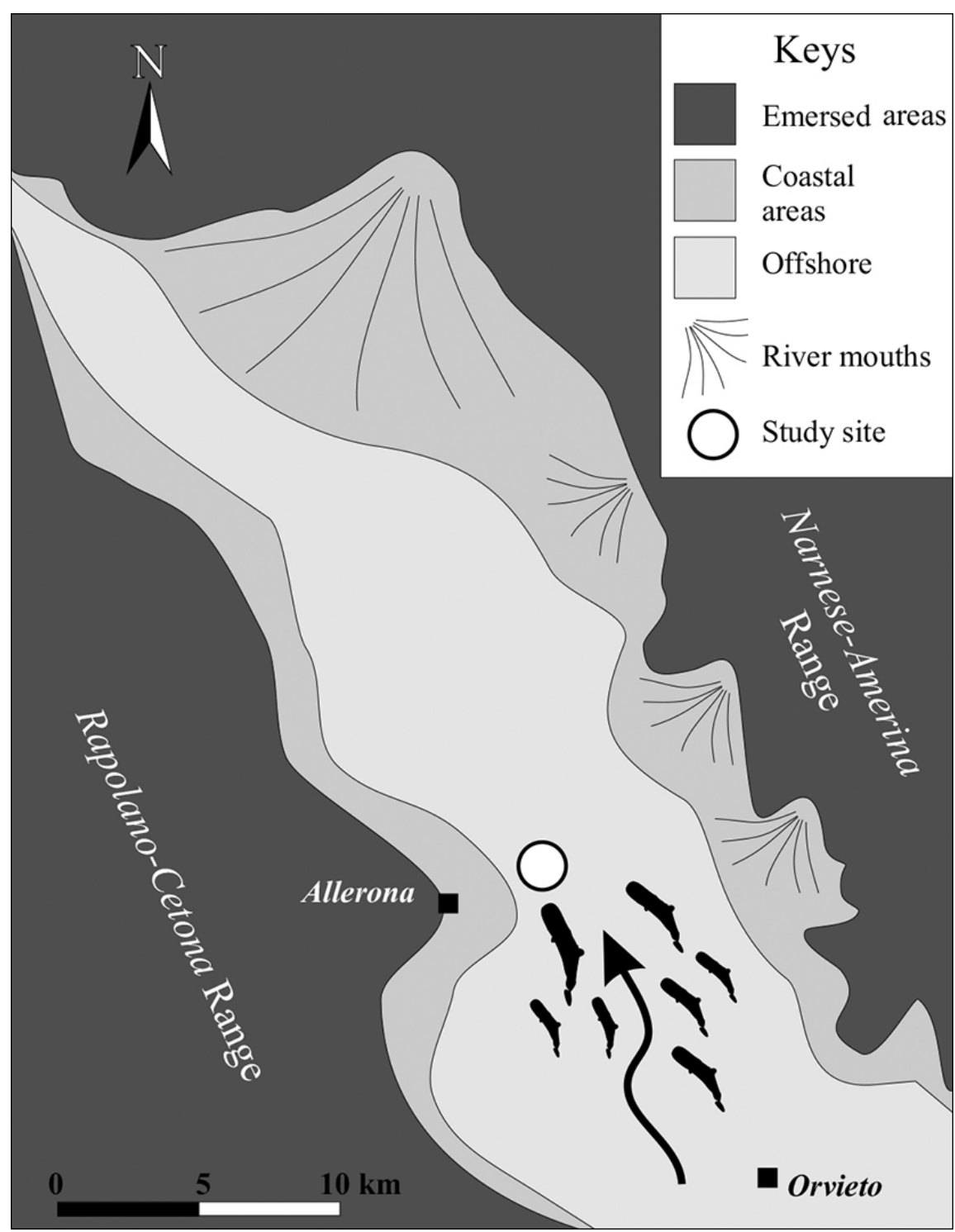

Figure DR4. Palaeogeographic configuration of the Allerona area, a narrowly elongated NW-SE bay ("cul-de-sac"), with a maximum depth of 150 meters and subject to river influx, which may have been a natural trap for pods of sperm whales chasing schools of squid. 